\title{
Investigação dos conceitos de religiosidade e espiritualidade em amostra clínica e não clínica em contexto brasileiro: uma análise qualitativa
}

\author{
Cristiane Schumann Silva Curcio \\ Alexander Moreira-Almeida
}

\section{RESUMO}

Introdução: Já é conhecido o papel (geralmente positivo) da religiosidade e espiritualidade (R/ E) sobre a saúde física e mental dos indivíduos, porém, mesmo com evidências robustas, não existe um consenso científico com relação aos conceitos de R/E, podendo levar a: instrumentos não acurados, ampliação ou "redução" dos conceitos a outros constructos que não necessariamente são R/E. Objetivo: avaliar de forma qualitativa os principais atributos que os conceitos de R/E possuem em uma amostra clínica e não clínica do contexto brasileiro. Métodos: 14 sujeitos, pacientes e acompanhantes de 2 hospitais gerais de Juiz de Fora-MG foram sorteados a partir de uma amostra prévia (estudo quantitativo) e responderam a um questionário semi-estruturado (10 questões) sobre os conceitos de R/E. Análise de conteúdo foi utilizada para as interpretações. Resultados: percebe-se insegurança para a definição dos conceitos (especialmente o de espiritualidade), a palavra 'fé' presente em muitos discursos, a importância dos aspectos religiosos privados na vida dos respondentes, a associação que os alguns participantes fizeram entre espiritualidade e espiritismo e a maioria acreditar haver algo além do mundo material, especialmente após a morte. Conclusão: fé, religiosidade não organizacional, religiosidade intrínseca e coping religioso espiritual foram as principais dimensões associadas aos conceitos de R/E.

Palavras-chave: religiosidade; espiritualidade; conceito; definição; amostra clínica.

\begin{abstract}
Introduction: The role of religiousness and spirituality (R/S) on the physical and mental health of individuals is already known (usually positive), but even with robust evidence among these associations, there is no scientific consensus regarding the concepts of R/S, a fact that leads to implications as: non-accurate measures, the extension, or "reduction" of the concepts to other constructs that are not necessarily R/S, besides clinical aspects that can confuse R/S with psychopathological aspects. Objective: to evaluate in a qualitative way, the main attributes that the concepts of religiousness and spirituality have in a clinical, and in a non clinical sample of the Brazilian context. Methods: 14 subjects, patients and caregivers from 2 general hospitals of Juiz de Fora-MG were sorted out from a previous sample (quantitative study) and responded to a semi-structured questionnaire about the concepts of religiosity and spirituality. Content analysis was used for interpretations. Results: the definition of the concepts (especially of spirituality) was confuse, the word 'faith' was present in many discourses, the importance of private religious aspects in respondents' lives, the association of spirituality with spiritism, and to believe there is something beyond the material world was very frequent. Conclusion: faith, aspects of private religiousness (non- organizational religiousness), intrinsic religiosity and spiritual religious coping, were the main dimensions of R/ $\mathrm{S}$ associated with the concepts of religiosity and spirituality.
\end{abstract}

Keywords: religiosity; spirituality; concept; definition; clinical sample.

\section{Sobre os Autores}

C. S. S. C.

orcid.org/0000-0002-0926-3750 Universidade Federal de Juiz de Fora (UFJF) - Juiz de Fora, MG crisschumann@gmail.com

\section{A. M. A.}

orcid.org/0000-0002-9135-2532 Universidade Federal de Juiz de Fora (UFJF) - Juiz de Fora, MG alex.ma@ufjf.edu.br

\section{Direitos Autorais}

Este é um artigo de acesso aberto e pode ser reproduzido livremente, distribuído, transmitido ou modificado, por qualquer pessoa desde que usado sem fins comerciais. 0 trabalho é disponibilizado sob a licença Creative Commons CCBY-NC. 


\section{N"INTERACÃO EM ET PSICOLOGIA}

De acordo com dados recentes, quatro de cada cinco pessoas (84\%) em todo o mundo, afirmam pertencer a uma denominação religiosa (Pew Research, 2012). Crenças relativas a Deus estar diretamente envolvido nas coisas que acontecem no mundo, chegam a $90 \%$ em países africanos, $78 \%$ em países da Europa Oriental e $61 \%$ no Brasil, atingindo níveis ainda mais elevados em nações islâmicas (Stark, 2015).

Já é conhecido o papel (geralmente positivo, mas também podendo ser negativo) da religiosidade e espiritualidade (R/E) sobre a saúde física e mental dos indivíduos (como: menores níveis de depressão, uso/abuso de álcool e outras drogas, ideação e comportamento suicida, maior sobrevida, melhor qualidade de vida e maiores níveis de satisfação com a vida.) (Idler, 1987; Dalgalarrondo, 2006; Moreira-Almeida, Lotufo Neto \& Koenig, 2006; Tsuang et al., 2007; Koenig, 2008; Lucchetti, Lucchetti \& Avezum, 2011; Koenig, King \& Carson, 2012). Estes dados são consistentes em amostras clínicas e não clínicas, incluindo pacientes e cuidadores (Koenig, McCulloug \& Larson, 2001; Koenig, King \& Carson, 2012), e mesmo com evidências robustas entre a associação de R/E e saúde, não existe um consenso científico com relação aos conceitos de R/E, fato que leva a implicações como instrumentos não acurados, a ampliação ou "redução" dos conceitos a outros constructos que não necessariamente são $R / E$, além de aspectos clínicos que podem "confundir" R/E com aspectos psicopatológicos.

Historicamente, espiritualidade não era distinguida da religiosidade até o surgimento do secularismo no século $X X$ (Turner, Lukoff, Barnhouse \& Lu, 1995). Nos últimos 50 anos, o interesse pela espiritualidade aumentou muito (Roof, 1993) e a abordagem atual destes conceitos enfoca as crenças, as emoções, as práticas e os relacionamentos dos indivíduos em relação a um poder superior ou um ser divino, o sagrado. O principal pesquisador na área de espiritualidade e saúde, Harold Koenig, define espiritualidade como uma busca pessoal pela compreensão das questões últimas acerca da vida, do seu significado, e da relação com o sagrado e o transcendente, podendo ou não conduzir ou originar rituais religiosos e formação de comunidades. Ele define religiosidade como um "organizado sistema de crenças, práticas, rituais e símbolos designados a facilitar a aproximação com o sagrado" (Koenig, McCulloug \& Larson, 2001). David J. Hufford, um dos maiores pesquisadores mundiais na área de crenças, especialmente crenças espirituais, define espiritualidade retomando a origem etimológica de 14 palavras: "espiritualidade se refere ao domínio do espírito", ou seja, à dimensão não material, extrafísica da existência que pode ser expressa por termos como: "Deus ou deuses, almas, anjos e demônios". Habitualmente se refere a "algo invisível e intangível que é a essência da pessoa". E religião é o aspecto institucional da espiritualidade, religiões são instituições organizadas em torno da ideia de espírito. Ele admite a existência de pessoas que seriam "espiritualizadas, mas não religiosas" e de pessoas que são extrinsecamente religiosas, mas não necessariamente espiritualizadas (Hufford, 2005, p. 10). Um dos principais autores atuais em psicologia da religião é Kenneth Pargament, que em 1997 definiu espiritualidade como "uma busca pelo sagrado" (p. 32) e religião como "um sistema organizado de crenças, práticas, rituais e símbolos projetados para auxiliar a proximidade do indivíduo com o sagrado e/ou transcendente e que pode, ou não, levar ao desenvolvimento de práticas religiosas ou formações de comunidades religiosas". Para Pargament, para ser espiritual, necessariamente precisa haver uma correlação com o Sagrado. Ele enfatizou ainda que a espiritualidade como uma dimensão crítica da vida que "não pode e não deve ser explicada" e pode ser concebida como "uma dimensão mais elevada do potencial humano" (Pargament, 2009, p. 31).

Assim, faz-se importante conhecer as variações desses conceitos no contexto brasileiro, pois isso ajudará a avaliar a validade das atuais medidas de R/E (muitas delas traduzidas ou baseadas em teorias estrangeiras) e/ou a desenvolver escalas mais apropriadas ao contexto deste país. Além disso, pode auxiliar clínicos e pesquisadores a conhecerem melhor o que os brasileiros entendem por religiosidade e espiritualidade para melhorarem suas compreensões sobre os pacientes, bem como potencializarem aspectos de R/E deles em prol de engajamento no tratamento e/ou ampliar resultados de saúde. Assim, o objetivo geral deste estudo é explorar qualitativamente o que uma amostra de brasileiros entende por religião, religiosidade, espiritualidade, o que é comum e o que é diferente entre esses conceitos; quais são os principais atributos que os conceitos de religiosidade e espiritualidade possuem no contexto brasileiro, especificamente em uma amostra clínica (de pacientes internados) e seus acompanhantes.

\section{MÉTODO}

Esta pesquisa faz parte de um estudo desenvolvido para a avaliação das propriedades psicométricas de uma escala de R/E para o português - a Brief Multidimensional Measure of Religiousness and Spirituality (Miarelli \& Silva, 2011; Curcio, 2013; Curcio, Moreira-Almeida \& Lucchetti, 2015) e a investigar os conceitos de Religiosidade e Espiritualidade a partir de correlações de dados quantitativos (com instrumentos validados de R/E) e de entrevista qualitativa.

A validação da BMMRS (Curcio, 2013; Curcio, MoreiraAlmeida \& Lucchetti, 2015) bem como a análise quantitativa 
dos aspectos conceituais de R/E (Curcio, 2018) estão descritas e discutidas em trabalhos específicos e o presente artigo objetiva apresentar os aspectos qualitativos do estudo.

A coleta dos dados qualitativos foi realizada entre agosto de 2016 e março de 2017, após aprovação do protocolo de pesquisa (no 2122.182.2010 e 52745115.5.0000.5147) pelo Comitê de Ética em Pesquisa (CEP) da Universidade de Juiz de Fora (UFJF). Houve assinatura do Termo de Consentimento Livre e Esclarecido nas duas etapas da pesquisa (quantitativa em 2011 e qualitativa em 2016).

A amostra total do estudo foi de 651 sujeitos, e a amostra para as entrevistas qualitativas foi extraída a partir das respostas para duas das dimensões da BMMRS- auto relato de religiosidade e de espiritualidade ("Você se considera uma pessoa religiosa?", com opções de resposta: muito religiosa, moderadamente religiosa, pouco religiosa, nem um pouco religiosa. "Você se considera uma pessoa espiritualizada?", com opções de resposta: muito espiritualizada, moderadamente espiritualizada, pouco espiritualizada, nem um pouco espiritualizada). A partir das respostas dos sujeitos, eles foram dispostos em 4 categorias: 1) Alta Religiosidade e Alta Espiritualidade, 2) Alta Religiosidade e Baixa Espiritualidade, 3) Baixa Religiosidade e Alta Espiritualidade e 4) Baixa Religiosidade e Baixa Espiritualidade. De cada uma dessas categorias, quatro sujeitos foram randomicamente sorteados para serem convidados a participar da entrevista semiestruturada de forma a se conhecer de modo mais aprofundado o universo de crenças dessas pessoas e seus valores e significados aos termos religiosidade e espiritualidade (Godoy, 1995; Demo, 1998; Martins, 2004). Quando um dos quatro entrevistados de cada categoria inicialmente sorteado não fosse encontrado ou se negasse a participar da entrevista, o sorteio de um novo membro da categoria foi realizado.

Para os sujeitos sorteados, que foram contatados primeiramente por telefone, a pesquisadora principal se identificou como psicóloga e responsável pelo desenvolvimento da pesquisa sobre religiosidade e espiritualidade que eles teriam participado em 2011/2012 nos hospitais supracitados, quando necessário, deu características como "quando você esteve internado no hospital X" ou "você se lembra que respondeu a um questionário sobre religiosidade?" e convidou-os para participar da nova etapa da pesquisa. Após a aceitação informal, em dia e horário agendados, a pesquisadora foi ao encontro do sujeito de pesquisa para a coleta dos dados ( $100 \%$ das entrevistas qualitativas foram realizadas pela pesquisadora responsável) e realizadas no domicílio do participante, com um dos entrevistados, no Hospital Universitário (por preferência do participante), ou por telefone (alguns participantes preferiram conceder a entrevista via telefone (dois), e outros (três) estavam morando em outra cidade, não vinham a Juiz de Fora regularmente e também foram entrevistados por telefone).

\section{Tabela 1. Quantidade de sujeitos em cada nivel de religiosidade e espiritualidade e quantidade de sorteados de cada categoria para a participação na pesquisa qualitativa}

\begin{tabular}{|c|c|c|c|c|}
\hline $\begin{array}{l}\text { Categorias/Nível } \\
\text { religiosidade espiritualidade }\end{array}$ & $\begin{array}{l}\text { N Total da } \\
\text { categoria }\end{array}$ & $\begin{array}{l}\% \text { na } \\
\text { amostra }\end{array}$ & $\begin{array}{l}\text { N Entrevistados por } \\
\text { categoria }\end{array}$ & OBS. \\
\hline $\begin{array}{l}\text { Alta Religiosidade e Alta } \\
\text { Espiritualidade }\end{array}$ & 10 & 1,6 & 4 & $\begin{array}{l}\text { Nenhuma recusa entre primeiros } \\
\text { sorteados }\end{array}$ \\
\hline $\begin{array}{l}\text { Alta Religiosidade e Baixa } \\
\text { Espiritualidade }\end{array}$ & 8 & 1,3 & 3 & $\begin{array}{l}2 \text { recusas ( } 1 \text { muito idoso e debilitado e } 1 \\
\text { não foi encontrado) }\end{array}$ \\
\hline $\begin{array}{l}\text { Baixa Religiosidade e Alta } \\
\text { Espiritualidade }\end{array}$ & 3 & 0,5 & 3 & Todos \\
\hline $\begin{array}{l}\text { Baixa Religiosidade e Baixa } \\
\text { Espiritualidade }\end{array}$ & 130 & 20,4 & 4 & 2 recusas \\
\hline $\begin{array}{l}\text { Moderada Religiosidade e } \\
\text { Espiritualidade }\end{array}$ & 506 & 76,3 & 0 & $\begin{array}{l}\text { Foco da coleta: graus polares de } \\
\text { religiosidade e espiritualidade e não } \\
\text { moderado. }\end{array}$ \\
\hline
\end{tabular}

$\mathrm{Na}$ maioria das entrevistas, a pesquisadora ficou a sós com o participante em um recinto para a coleta dos dados, mas houve circunstâncias de interrupções da entrevista por parte de familiares para pedir auxílio ao participante para a resolução de alguma questão cotidiana.
Os principais motivos apontados para a recusa foram: falta de saúde, falta de tempo para receber a pesquisadora e/ ou falta de interesse em participar da pesquisa.

0 instrumento de pesquisa possui 10 questões (como se vê a seguir) e todas as entrevistas foram gravadas em mídia 


\section{-4: INTERACÃO EM LF PSICOLOGIA}

eletrônica e posteriormente transcritas na íntegra para análise dos dados.

As entrevistas semiestruturadas duraram em média 26 minutos (média realizada por entrevistas realizadas em domicílio (quatro medições) e telefone (três medições).

Anotações sobre observações de campo foram registradas imediatamente após a entrevista, quando a pesquisadora já não estava mais na presença do participante.

A seguir, as 10 questões norteadoras da entrevista qualitativa:

(1) 0 que você entende por religião?

(2) O que você entende por religiosidade?

(3) O que você entende por espiritualidade?

(4) Qual é a relação entre os termos religiosidade e espiritualidade? 0 que é comum entre eles? 0 que é diferente entre eles?

(5) É possível uma pessoa ser espiritualizada sem necessariamente ser religiosa? Como?

(6) É possível uma pessoa ser religiosa sem necessariamente ser espiritualizada? Como?

(7) A sua Espiritualidade/Religiosidade mudou desde 2011/2012? O que mudou nela? Que fatores contribuíram para esta mudança?

(8) O que dá significado à sua vida?

(9) $\mathrm{Na}$ sua opinião, depois que a gente morre, o que acontece?

(10) Você gostaria de acrescentar alguma coisa à esta entrevista?

Essas perguntas foram os temas-eixo das entrevistas qualitativas e foram criadas a partir de leitura de textos históricos e científicos sobre a temática, e em parceria com o orientador, com base nos objetivos do estudo descritos acima.

Os temas-eixo foram definidos a priori a partir dos objetivos da pesquisa, com abertura para que novas categorias fossem adicionadas (ou categorias fossem retiradas) a partir da análise dos dados. A técnica utilizada para análise dos dados qualitativos seguiu a proposta metodológica da análise de conteúdo do tipo estrutural e temática, caracterizada pela sistematização e rigor metodológico (Bardin, 2011), e foi organizada em três etapas: na primeira, a pré-análise, ocorreu a sistematização e a organização das ideias iniciais, através da leitura "flutuante" do material para uma primeira avaliação das categorias definidas a priori; a segunda etapa se referiu à exploração do material, sendo uma fase marcada essencialmente por operações de categorização (confirmar, adicionar ou excluir categorias previamente definidas); na última etapa, o tratamento dos resultados, que se deu através de inferências e interpretações baseadas nos objetivos previstos, resultados encontrados e literatura/referencial na área (Bardin, 2011).

Os dados qualitativos serão apresentados a partir do seguinte esquema:

Sexo; Idade; Hospital; Categoria de religiosidade e espiritualidade:

$$
\begin{aligned}
& M=\text { mulher } \\
& H=\text { homem } \\
& H U=\text { Hospital Universitário } \\
& H P=\text { Hospital Privado } \\
& R E=\text { Alta religiosidade e alta espiritualidade } \\
& \text { Re = Alta religiosidade e baixa espiritualidade } \\
& r E=\text { Baixa religiosidade e alta espiritualidade } \\
& r e=\text { Baixa religiosidade e baixa espiritualidade } \\
& \text { Exemplo: M34HP- Re. }
\end{aligned}
$$

\section{RESULTADOS}

A A apresentação dos resultados será feita a partir da análise e compilação das respostas de cada pergunta/eixo.

\section{1) ENTENDIMENTO DE RELIGIOSIDADE}

A grande maioria dos entrevistados relacionou o conceito de religiosidade à religião ou à prática religiosa no dia a dia. Observou-se que os entrevistados falaram quase que unanimemente de fé (apenas um participante não relatou essa palavra). Alguns disseram que religiosidade é a ligação com Deus e ressaltaram que seria a prática de preceitos da religião no cotidiano (12 entrevistados). Nessa categoria de respostas, não se observaram diferenças entre os níveis de religiosidade e espiritualidade ( $\mathrm{RE} / \mathrm{Re} / \mathrm{rE} / \mathrm{re}$ ) pois foram praticamente unânimes os padrões de respostas de todos os entrevistados.

\section{Religiosidade atrelada a religiões [unânime]}




\section{W'INTERACCÃO EM ET PSICOLOGIA}

“Bom, religião? Assim, pra mim, ah... é... Eu sempre fui criada no (pausa), no, na, no catolicismo, né?!" (M25HPre)

"Religiosidade eu acredito que seja... é... a sua imersão dentro da própria religião. Eu acho que a pessoa pode acreditar com a crença em algo mas não se (pausa) necessariamente ter religiosidade." (H56HP- rE)

\section{Fé [13 participantes]}

"Eu fui criada e assim, aprendi a rezar desde sempre, ter fé." (M25HP-re)

"Fé é... Fé tá em primeiro lugar, né? Pra mim a fé tá em primeiro lugar. Deus e a fé, pra mim, em primeiro lugar. Acho que a gente sem Deus não é nada, né... Pra mim é" (M75HU-RE)

\section{Prática da religião no dia a dia [nove participantes]}

"Religiosidade é você é... Acreditar e praticar o seu, o seu credo, né...É...Cada pessoa, no caso, segue uma religião. Um segue cristianismo, outro budismo, é, espiritismo que é o meu caso, e ter essa reli..(pausa) religiosidade seria você, é... colocar isso na sua vida, no seu dia a dia." (M46HP-rE)

\section{2) ENTENDIMENTO DE ESPIRITUALIDADE}

Observou-se que a conceitualização de espiritualidade fol mais diversificada e imprecisa do que a de religiosidade. Alguns participantes disseram não saber conceituar (dois participantes), ou expressaram suas opiniões com muita insegurança (três participantes), ou preferiram nem arriscar a emitir uma opinião (dois participantes). Também houve relação com religião e a identificação do caráter subjetivo e intrínseco do termo espiritualidade. Mais uma vez, aqui, a fé apareceu fortemente associada ao conceito. Foi comum associarem espiritualidade ao Espiritismo (religião bastante praticada no Brasil $\left(3^{a}\right)$, que tem como pressupostos principais a mediunidade e a reencarnação). Nesta categoria de respostas, fé não se diferenciou entre participantes com diferentes níveis de religiosidade/espiritualidade e nem com relação à confusão ou insegurança para responder à pergunta em questão, porém, observou-se que aqueles que tendiam a associar espiritualidade a espiritismo eram basicamente aqueles com alta religiosidade e baixa espiritualidade $(\mathrm{Re})$ e alguns com alta religiosidade e espiritualidade (RE) e geralmente eram os evangélicos.

\section{Fé [13 participantes]}

\section{Cristiane Schumann Silva Curcio e Alexander Moreira-Almeida}

"É um exercício de fé, se for no sentido, é, religioso. Se for no sentido filosófico eu acho que já tem outra conotação, já é algo que você traz pra você como um sentido da vida, como uma, uma, uma proposta de vivência, talvez seja isso" (H56HP-rE)

"Eu acho que isso aí é acreditar, entendeu? Ter fé, acreditar em Deus" (H7OHU- rE)

\section{Confusão/insegurança [sete participantes]}

"Se eu disser que nada...Não entendo nada mesmo (risos). Se eu tivesse fazendo uma prova valendo dez eu ia ganha zero porque eu também não sei responder não (risos)" (M47HU-re)

Ah, espiritu (pausa) alidade... Ué... isso aí, espiritualidade é eu vou ficar te devendo, porque como que eu posso te falar isso aí..." (H7OHU-rE)

\section{Espiritismo}

Nove participantes fizeram de alguma forma, uma relação entre espiritualidade e espiritismo.

“Espituralidade... (sic) Então, eu acredito no espírito,... O espírito se reencarna..."(M66HU- RE)

“(...) porque já fui muito em espiritualidade, depois eu abandonei, nunca mais fui..."(M75HURE)

“Espiritualidade?...Macumba eu não gosto não, nunca gostei. Eu sei que (pausa) muitas pessoas que são espíritas, mas eu gosto, eu vou ser sempre católica apostólica romana, foi a religião que a minha mãe passou pra minha cabeça" (M55HURe)

“Espiritualidade é quem recebe espírito, né?"(H36HURe)

\section{3) SEMELHANCCAS E DIFERENÇAS ENTRE RELIGIOSIDADE E ESPIRITUALIDADE}

Mais uma vez essa questão despertou dúvidas, confusões e insegurança nos entrevistados. Observaram-se três padrões de respostas principais: aqueles que diziam que $\mathrm{R}$ e $\mathrm{E}$ eram a mesma coisa; aqueles que diziam que $\mathrm{R}$ e $\mathrm{E}$ eram conceitos distintos e explicavam ressaltando o caráter mais institucional da religiosidade e o subjetivo da espiritualidade; aqueles que separavam os termos e faziam julgamento de valor quanto a eles, dizendo que religiosidade seria algo de Deus e espiritualidade como algo demoníaco, "mexer com espírito". Aqueles que tenderam a associar espiritualidade a espiritismo foram basicamente aqueles 


\section{W INERACÄOEM PSICOLOGIA}

pertencentes à categoria de $\mathrm{Re}$ e $\mathrm{RE}$, sendo comumente evangélicos.

\section{$\mathrm{R} /$ E como a mesma coisa [cinco participantes]}

“Pra mim significa a mesma coisa” (H36HU-Re)

\section{$\mathrm{R} / \mathrm{E}$ como coisas distintas e espiritualidade como algo mais intrínseco [três participantes]}

“Espiritualidade não está atrelada com religiosidade, é a busca de conexão com algo maior. Religiosidade está relacionado a religião. Espiritualidade pode ou não estar ligada a religiosidade, te dá mais liberdade, ela não limita. O ponto comum é a busca de conexão com algo maior." (M46HP-rE)

"Espiritualidade eu acho que é uma coisa que vem mais de dentro, assim, é uma coisa que você sente mais, que (pausa), que, vem, parte mais de você assim, sem outra pessoa vir e te falar o que que é, assim... E religiosidade é mais uma coisa que alguém fala e você acredita, de uma certa forma, e segue aquele conceito, assim..." (M25HPre).

\section{$\mathrm{R} /$ E como coisas distintas, Espiritualidade como espiritismo [nove participantes]}

"Nunca gostei. Eu não gosto de macumba, essas coisas eu não gosto não" (M55HU-Re)

"o que é comum entre o espírito e o religioso né? Eu acho que a diferença é pouca né? se você tem fé, se você acredita, se você busca, tudo é válido! cê entendeu? tanto no espírito quanto na, na religião né? Quer dizer, Deus né?" (M66HU-RE)

\section{4] POSSIBILIDADE DE ALGUÉM SER ESPIRITUALIZADO SEM SER RELIGIOSO [OITO PARTICIPANTES)}

A maioria dos entrevistados respondeu que é possível uma pessoa ser espiritualizada sem ser religiosa, porém, poucos apresentaram segurança para explicar como se daria essa relação. Alguns voltaram a remeter espiritualidade ao espiritismo e que, portanto, seria sim possível alguém ser espiritualizado (espírita) sem ser religioso.

Basicamente, aqueles que responderam ser possível alguém ser espiritualizado sem ser religioso eram os participantes com baixa religiosidade ( $r E$ ou re). Mais uma vez, os pertencentes a $\mathrm{Re}$ ou RE foram os que atrelaram espiritualidade a espiritismo.

\section{Ir à igreja x ter fé (3 participantes]}

Os participantes reiteraram que o que importa seria a pessoa ter fé e não necessariamente ir a uma igreja, não necessariamente ter religiosidade organizacional.

"Por exemplo, eu acredito em Deus, né, tenho fé em (pausa) em muitas coisas, assim, até conceitos mesmo da igreja católica, do espiritismo, assim, de, (pausa), de, religiões diferentes, então eu acho que é isso que importa, a pessoa ter fé, né? e acreditar naquilo, e não necessariamente você precisa ter uma religião pra falar 'eu sou...' né, eu acho que você tem que, o importante é ter fé nas coisas, assim..." (M25HP-re)

\section{Compreensão dos aspectos humanos $X$ participação religiosa}

Um dos participantes (o único que se nomeou como ateu materialista), ressaltou o aspecto humano da espiritualidade que não necessariamente tem relação com aspectos religiosos.

"Você ser uma pessoa humana no sentido de compreender os afetos, as necessidades, as dificuldades da existência humana sem estar atrelado a um conceito religioso de pós vida, né, um conceito de que você vai ser compensado ou punido depois de sua existência eu acho possível você ser uma pessoa espiritualizada no sentido filosófico da existência e não no sentido religioso, eu acho que..." (H56HP-rE)

\section{Espiritualidade e espiritismo [nove participantes]}

"Eu acho que é, pra mim eu acho que tem sim. Eu conheço muita gente que não é religiosa e é espiritualizada, só meche com espiritismo... Porque espiritismo tem pessoa que só vive através do espiritismo, fazendo particular pros outros, só meche com isso..." (H36HU-Re)

\section{5] POSSIBILIDADE DE ALGUÉM SER RELIGIOSO SEM SER ESPIRITUALIZADO [8 PARTICIPANTES]}

A grande maioria disse que é possível. Algumas pessoas disseram do aspecto "extrínseco" da religiosidade e que a pessoa seria religiosa pelos 'benefícios' que isso poderia trazer (dois participantes $\mathrm{rE}$ ). Outros fizeram a mesma interrelação com o espiritismo e outras religiões. 0 mesmo padrão ( $R e$ e $R E$ ) com relação a atrelar espiritualidade a espiritismo se apresentou também nesta categoria de respostas. 


\section{-4* INTERACÃO EM LF PSICOLOGIA}

\section{Espiritualidade como bondade, moral [4 participantes]}

Alguns participantes, mesmo aqueles que relacionaram espiritualidade a espiritismo, disseram que a intenção do coração, a bondade e comportamentos moralmente adequados possibilitariam alguém ser espiritualizado sem ser religioso.

"A pessoa que tenha essa religiosidade, é, dentro dela mas que ela não pratica, não tem essa espiritualidade, a espiritualidade no conceito de você ser uma pessoa é...do bem, que pratica coisas boas." (M46HP-rE)

\section{Caráter "extrínseco" da religiosidade [3 participantes]}

"Eu cheguei a um tempo, assim, de eu frequentar mais a igreja mas sem (pausa) entender muito bem o que que eu tava fazendo lá. Porque eu ia lá mais pra, escutar, mas eu não conseguia compreender direito 0 que que, eles falavam, então eu acho que, você ser religioso mas não ter, é... Espiritualidade é mais isso, você (pausa), eu falar "eu frequento a igreja" e tudo mas eu não... Eu vou lá mais pra ir mesmo, assim, talvez até me sinto bem mas... Não tem uma fé naquelas coisas que eles pregam." (M25HPre)

"Ah, eu acho que entra um pouco de cinismo nisso aí... Conheço algumas pessoas que se dizem religiosas que não tem nenhuma, nenhum sentimento por ninguém." (H56HP-rE)

\section{Espiritualidade e espiritos, conceito de bem e mal Coito participantes]}

Dos nove participantes que ligaram espiritualidade a espiritismo, apenas um deles era espírita e fez uma correlação "positiva" entre espiritismo e espiritualidade. Os demais correlacionaram espiritualidade e consequentemente espiritismo com algo mal, "que não se deveria mexer".

"Espiritualidade pra mim é só o único Espírito Santo, né? Tem espírito do mal, né? E espírito do bem. (M27HU-re)

"Eu acho que (pausa) é bem diferente,. Tem gente que gosta do espiritismo, e outros não." (M75HU-RE) (Linguagem não verbal - expressão facial de desaprovação com relação ao espiritismo).

\section{6) MUDANÇA DA RELIGIOSIDADE/ESPIRITUALIDADE}

Esta categoria foi extraída da pergunta "a sua religiosidade ou espiritualidade mudou do tempo da internação para cá?". Alguns disseram que sua R e E aumentou após 2011 (possível doença/causa da internação), uma das entrevistadas disse que diminuiu após a perda do irmão (o qual ela estava acompanhando no hospital no primeiro momento da coleta dos dados) e outros (maioria) disseram que não houve mudança. Percebe-se um coping religioso espiritual para lidar com doenças e perdas. Não se observou distinção entre os participantes com diferentes níveis de religiosidade/espiritualidade nesta categoria de respostas.

\section{Aumento [4 participantes]}

"Ah, mudou muito. A minha fé cresceu mais entendeu? a minha fé cresceu; o meu crer, aumentou muito mais, porque eu, eu tive como prova ela (filha que ficou curada)... ali eu chorava e, e pedia a Deus e pedia a Deus um milagre, um milagre, um milagre... o milagre veio!!!" (M66HU-RE)

\section{Diminuição [1 participante]}

"Fui quando eu perdi ele (irmão), que realmente eu tava precisando de um conforto e tudo, mas depois que passa esse período de luto eu meio que me afastei..." (M46HP$\mathrm{rE})$

\section{Não mudou [9 participantes]}

“Não, não mudou nada não. Eu sou ateu, sempre, né" (H56HP-rE)

"Não mudou... eu pude perceber que quando a gente faz algo para a outra pessoa, igual eu fiz pra ele (esposo que estava doente) e faço pra qualquer outra pessoa, eu acho que o espírito da gente, a alma se... ela se... é, se entrega, ela se entrega totalmente para Deus." (M59HP-RE)

\section{7) SIGNIFICADOÀ VIDA}

Percebeu-se uma importância grande da fé e de Deus como dando significado a tudo, inclusive ao sofrimento. Família também foi um ponto muito citado como fonte significado para a vida. Paz interior e tranquilidade também foram levantados pelos entrevistados. Uma participante relatou estar desempregada e com uma filha pequena e citou que um trabalho traria mais sentido, e um outro que trabalha como cuidador também ressaltou a importância do trabalho para ele próprio, por achar importante ajudar pessoas. A 


\section{W'INTERACÃO EM IT PSICOLOGIA}

palavra (ou sinônimos) fé foi muito presente entre os participantes de todos os níveis de religiosidade e espiritualidade. Cultura foi citada apenas pelo participante que se auto denominou "cético" (re).

\section{Amor e fé [9 participantes]}

Vários entrevistados disseram que o amor e a fé (quatro se reportando aos dois conceitos de forma conjunta e outros cinco se referindo apenas à fé) são o que dá sentido à vida deles.

“O amor e a nossa fé!" (M66HU-RE)

“É a fé... sem a fé nós não vivemos, porque problemas nós vamos encontrar com a fé ou sem fé, mas quando a gente tem fé, a gente supera qualquer problema na vida." (M59HP-RE)

\section{Familia e amigos}

Dentre os entrevistados, oito se reportaram a família, filhos, pais etc. como o que dá sentido à vida deles, e três também disseram que as amizades têm este atributo.

"Minha família, meus amigos, minha vontade, meu desejo de crescer" (M46HP-rE)

"É a minha família, porque é eles que me dá força, eu acho que o que tem é eles". (M47HU-re)

\section{Deus}

Dentre os participantes, quatro responderam diretamente com a palavra Deus como aquilo que dá sentido à vida deles.

“Deus pra mim é tudo, Cristiane. Deus é tudo na vida da gente... Pra mim Deus é tudo. Eu sou feliz. Já tenho meu filho, meu marido" (M55HURe)

"Por exemplo, eu acredito em Deus, né, tenho fé"(M25HPre)

"A gente sem Deus não é nada, né" (M47HURe)

\section{Cultura}

0 único participante que se nomeou como ateu materialista ressaltou o aspecto que a cultura, especialmente a música, tem para trazer significado à vida dele.

"É.. eu acho que a, a existência da gente ela, no plano

\section{Cristiane Schumann Silva Curcio e Alexander Moreira-Almeida}

filosófico, eu acho que a cultura no assim... No sentido da leitura, da música, da... (pausa) isso me dá, suporte pra... principalmente a música... Né... Ela me dá suporte pra... Pra, pra atravessar alguns momentos de reque... (pausa) né, que todos temos, desses momentos de oscilação da vida, né..." (H56HP-rE)

\section{Saúde}

Um dos participantes ( $\mathrm{rE}$ ) destacou que o seu processo de melhora, a sua saúde atual e o poder viver uma vida tranquila com a família são o que dão sentido à sua vida.

“É eu poder viver uma vida boa, tranquila, (pausa), com a minha família, e... (pausa)... Sem, sem problemas, entendeu? Uma pessoa saudável, que graças a Deus eu fiquei bem" (H7OHU-rE)

\section{8) O QUE ACONTECE DEPOIS QUE MORREMOS?}

Este tópico também deixou os entrevistados confusos e/ ou inseguros para responderem. Houve controvérsias com relação à finitude e à continuidade da vida. A grande maioria (13 participantes) disse frases que remetem à continuidade da vida (alma, céu, espírito, imortalidade ou reencarnação) após a morte do corpo físico e apenas um entrevistado disse que a morte do corpo físico significa o fim da existência ( $\mathrm{rE}$ ). Houve, com frequência, mesmo que implicitamente, os conceitos de céu e inferno.

\section{Após a morte, o espírito vai para algum lugar Chospital, céu,} inferno]

"Após a morte, há o desligamento do corpo físico com o espírito e os nossos níveis de desenvolvimento vai determinar o local para onde o espírito vai... hospitais para se curar ou ter consciência de que já não é mais o fulano" (M46HP-rE)

"Ah, depois que a gente morre...? A gente nã (pausa) não volta na terra mais não, né...Não vive mais não...A gente fica (pausa) a gente tá na casa de Deus, né..." (M47HU-Re)

"O espírito ou ele sobe ou ele desce... Só, pois é. A matéria se acaba, né? Que a gente só... O corpo da gente é só uma matéria, você entendeu? 0 espírito, o espírito não morre... Você entendeu?" (H36HU-Re)

"Depois que a gente morre? Ovo (ouço) falar tanto coisa, mas eu acredito que a gente vai pro paraíso né? Né? Num tem...Não tem volta!" (M66HU-RE) 


\section{W'INTERACÃO EM ET PSICOLOGIA}

Finitude

"Hum... morre... hum... A natureza cuida do resto. É... (pausa) é fim. Acabou, a sua existência foi cumprida, né?" (H55HP-rE)

\section{Incertezas e dúvidas}

Mesmo entre aqueles que emitiram uma opinião específica sobre o que acham que acontece conosco após a morte, foi muito constante (11 participantes) o destaque para dúvida com relação a isso, como ser apenas uma crença, um mistério, ou questões desse tipo.

"Nossa... Ai... É uma dúvida muito grande (risos). Bom, eu já cheguei a acreditar assim, até por (pausa) pelo fato da minha mãe ser espírita, (pausa) era espírita ela sempre me falava, que existia vida após a morte, eu já cheguei a acreditar um pouco nisso. Mas hoje... Acho que eu não acredito muito não. Mas assim, também não desacredito...mas eu não acredito muito que existe uma vida após a morte, mas também não acho que a gente morre e acaba tudo..." (M25HP-rE)

“O nosso espírito, ele vai pra junto de Deus, né... mas nós não temos essa certeeeeeza absoluta no nosso coração, porque tudo é um mistério e o mistério de Deus, só ele... que sabe." (M59HP-RE)

\section{9) ACRÉSCIMOS À ENTREVISTA}

Uma última questão da entrevista semi-estruturada era se o participante gostaria de acrescentar algo, e cinco participantes fizeram suas contribuições. Dois deles disseram que "o mundo está como está", pois está necessitando de Deus, de fé. Dois deles disseram que ter fé seria mais importante do que necessariamente praticar uma religião. E dois dos participantes ressaltaram a importância de se estudar o tema (mesmo sem serem pessoas religiosas) e parabenizou os pesquisadores pelo estudo.

\section{OBSERVAÇÕES GERAIS DAS ENTREVISTAS QUALITATIVAS}

De acordo com a observação da pesquisadora durante seu trabalho de campo, percebeu-se uma grande presença de coping religioso espiritual (12 participantes) até mesmo no participante ateu; ele disse reconhecer o papel da religiosidade/espiritualidade na vida das pessoas, para ajudalas a lidar com problemas, apesar dele próprio não utilizá-la como recurso.

“Porque problemas nós vamos encontrar com a fé ou sem fé, mas quan...quando a gente tem fé, a gente...né?
Cristiane Schumann Silva Curcio e Alexander Moreira-Almeida

supera qualquer problema na vida" (M59HPRE)

" Se eu não tivesse a fé que eu tenho em Deus, o que ser (pausa) teria sido de mim, que eu descobri que estava com problema de saúde?" (M55HURe)

Observou-se que a presença de coping religioso negativo foi pequena durante as entrevistas qualitativas. Apenas uma das participantes se remeteu ao fato de já ter pensado que Deus a abandonou:

"Tem hora que a gente fala Deus abandonou a gente, por exemplo, agora nós estamos achando que Deus abandonou porque caiu tudo, caiu a casa de uma vez, então..." (M47HUre)

$\mathrm{Na}$ amostra estudada observou-se também muito sincretismo religioso. Em muitas casas ou leitos visitados observou-se a presença de elementos religiosos de diferentes religiões (quadros com buda e imagens de santos católicos no mesmo ambiente, ou a presença de Bíblia evangélica e Livro dos Espíritos, e/ou Bíblia católica; terço de Nossa Senhora pendurado na cama, mas tocando hinos evangélicos no ambiente), exemplificando a presença do sincretismo religioso.

\section{DISCUSSÃO}

A partir das respostas às entrevistas, percebe-se que o conceito de religiosidade foi mais relacionado às religiões, práticas religiosas no dia a dia, e à fé. Tal achado é coerente com os dados quantitativos, nos quais o auto relato de religiosidade se relacionou com religiosidade nãoorganizacional e intrínseca (Curcio, 2018). Percebeu-se mais insegurança na definição do conceito de espiritualidade do que no de religiosidade. Espiritualidade também foi correlacionada à fé, mas um dos dados que mais chamam a atenção é a correlação entre o termo espiritualidade e espiritismo. Talvez pelo radical das palavras (espirit-) ser o mesmo, as pessoas podem inferir que são o mesmo construto. Além disso, o Espiritismo utiliza o conceito de espírito(s) de uma forma mais evidente do que católicos ou protestantes, e as pessoas poderiam relacionar espírito (como o Espiritismo vê) à espiritualidade. Uma outra possível explicação para esta correlação é que "espiritualidade" é um termo que os próprios espíritas kardecistas utilizam para se referirem aos "espíritos superiores em conjunto". Comparando as entrevistas com os dados quantitativos (Curcio, 2018) foi relevante e coerente notar que na análise multivariada, foram exatamente as variáveis filiação religiosa, religiosidade não organizacional e coping religioso espiritual (elementos extremamente presentes nas entrevistas qualitativas) que mantiveram relevância estatística com ser 


\section{H. INTERACÃO EM L PSICOLOGIA}

religioso e ser espiritualizado.

No que diz respeito à similaridade ou diferença entre os conceitos de religiosidade e espiritualidade, ou os participantes tendiam a ver ambos como sendo a mesma coisa, ou tendiam a diferenciá-las associando a espiritualidade a espiritismo, especialmente entre aqueles com alta religiosidade e alta espiritualidade e entre aqueles com alta religiosidade e baixa espiritualidade e/ou fazendo julgamento de valores como sendo a religiosidade algo "bom" e espiritualidade algo "mau". E alguns diferenciaram os conceitos dizendo que a religiosidade está mais ligada à prática religiosa e espiritualidade mais ligada a aspectos subjetivos e intrínsecos, que não necessariamente precisam estar associados a filiação religiosa, exatamente como o encontrado pelos dados quantitativos.

Com relação a uma pessoa poder ser espiritualizada sem ser religiosa ou ser religiosa sem ser espiritualizada, também se percebeu insegurança e dúvidas. Alguns diziam que sim, mas não conseguiam explicar ou exemplificar. Poucos levantaram o caráter mais "utilitário" da religiosidade sem espiritualidade, exemplificando com o caso de pessoas que vão frequentemente a serviços religiosos, mas que têm comportamentos amorais. Percebeu-se também que a categoria com alta espiritualidade e baixa religiosidade (na análise qualitativa) representa bem o grupo de "spiritual but not religious" descritos por Roof (1993) e Erlandson (2000).

Na questão sobre o que dá sentido à vida, amor, fé, Deus, família, amigos, trabalho, cultura ou saúde foram os elementos citados. Percebeu-se que muitos participantes citaram a palavra fé, de acordo com um modelo proposto por Newman (2004), espiritualidade e religião seriam função da fé, requereriam fé como fundamento, seria o princípio orientador pelo qual os indivíduos seriam religiosos ou espiritualizados.

Em grande parte das entrevistas a continuidade postmortem da vida apareceu de alguma forma (a pessoa dorme até o julgamento final, ou vai para o céu ou para o inferno). Apesar dessas opiniões, os entrevistados ressaltaram que eram meras opiniões, que na verdade há um mistério no que concerne à morte e que, portanto, eles não poderiam afirmar com $100 \%$ de certeza o que acontecerá conosco após a morte do corpo físico. Apenas dois entrevistados consideraram a morte o fim da existência. Esse achado qualitativo foi compatível com os achados dos dados quantitativos, onde a grande maioria da amostra disse acreditar em elementos imateriais (transcendência) e na continuidade da vida mesmo após a morte (Curcio, 2018; Curcio \& Moreira-Almeida, 2018).

Por ser um estudo que envolve participantes de Juiz de Fora $(M G)$ e seu entorno e por ter sido realizado em um contexto hospitalar, é necessário cautela na extrapolação desses achados para outras populações. Entretanto, a amostra grande e diversificada (clínica e não clínica, pessoas de diferentes origens socioeconômicas, provenientes de um hospital público e um hospital privado) acrescenta validade externa e fortalece as comparações com outros estudos. Por se tratar de um estudo transversal, é necessário que inferências causais sejam evitadas e/ou feitas com bastante cautela.

Percebeu-se na coleta dos dados qualitativos uma forte presença de coping religioso espiritual no discurso dos participantes, por várias vezes, os entrevistados se reportaram ao papel de Deus, da fé para lidar com problemas pessoais (inclusive com o adoecimento e ou luto do ente decorrente da internação no primeiro período da coleta dos dados), dado que também aparece na análise quantitativa, com relação ao auto relato de espiritualidade.

Observou-se bastante sincretismo religioso; em muitas casas ou leitos visitados, elementos religiosos de diferentes filiações religiosas (quadros com Buda e imagens de santos católicos no mesmo ambiente, ou a presença de Bíblia evangélica e livro dos espíritos, e/ou Bíblia católica; terço de Nossa Senhora pendurado na cama, mas tocando hinos evangélicos no ambiente) foram observados, fatos que vão ao encontro dos dados referentes sincretismo religioso no Brasil (Ferretti, 2001; Moreira-Almeira et al., 2010).

Nas entrevistas qualitativas, tanto pela fala quanto pela linguagem não verbal dos entrevistados, percebeu-se muita insegurança, confusão, fuga de palavras, pausas e contradições na definição de religiosidade e espiritualidade. Parece que a falta de clareza ou de consenso com relação à definição destes termos estendem-se do contexto científico para a população geral, e também entre clínicos.

A pesquisadora não observou diferença (conteúdo das respostas, espontaneidade para falar ou interesse em colaborar) entre as entrevistas realizadas pelo telefone e nas entrevistas pessoais.

Os achados deste estudo ilustram a necessidade de os pesquisadores e clínicos conhecerem os vários significados atribuídos à religiosidade e à espiritualidade por diferentes grupos religiosos e culturais, e as diferentes maneiras pelas quais esses grupos se consideram religiosos e/ou espirituais. Se alguém se considera religioso ou espiritualizado, depende do significado e da relevância desses termos para os membros de um determinado grupo religioso ou ideológico. Assim, para medir com precisão a religiosidade e a espiritualidade, torna-se necessário considerar a peculiaridade do sistema de crenças ou visões de mundo dos indivíduos ou grupos estudados.

Os dados encontrados neste estudo nos remetem a 


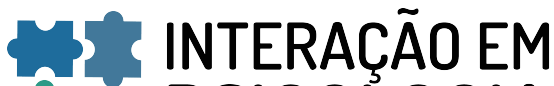 PSICOLOGIA}

reflexões com relação às implicações desses achados, tanto para o público em geral quanto com relação a pesquisas futuras. Diante da complexidade dos constructos, da multidimensionalidade, da multipotencialidade e da grande correlação entre os conceitos de religiosidade e espiritualidade seria adequado requerer um consenso científico mundial sobre os conceitos de religiosidade e espiritualidade? Qual seria a finalidade deste consenso? Ao "reduzir" o conceito de religiosidade e/ou de espiritualidade a um único conceito, não estaríamos perdendo algumas nuances de conceitos tão complexos? Em contrapartida, se esses conceitos forem muito ampliados para abarcar a complexidade destes constructos, não se recairia no fato de que tudo poderia ser encaixado como religiosidade ou espiritualidade?

Futuras pesquisas precisam escolher o conceito de R/E que mais se adeque aos objetivos da pesquisa, descrever 0 que estão chamando de religiosidade e de espiritualidade e especialmente, escolher medidas precisas (de preferência multidimensionais) e validadas para a mensuração desses constructos para que a variedade, complexidade e multipotencialidade dos conceitos de religiosidade e espiritualidade sejam alcançados da melhor maneira possível.

Além disso, pondera-se a possibilidade de maior divulgação dos possíveis conceitos de religiosidade e espiritualidade para o público em geral, de forma que as pessoas se sintam menos inseguras com relação à definição desses conceitos e para que consigam fazer uma melhor distinção entre espiritualidade e espiritismo.

\section{CONCLUSÃO}

A fé apareceu como elemento central nas entrevistas qualitativas para a definição tanto de religiosidade quanto de espiritualidade. Práticas privadas de religiosidade (religiosidade não organizacional) também foram muito relevantes nas entrevistas qualitativas, e foram também associadas tanto ao auto relato de religiosidade quanto de espiritualidade nas análises quantitativas. O conceito de religiosidade foi bastante relacionado à religião, mas o caráter desse envolvimento seria mais privado (religiosidade não organizacional) e intrínseco (religiosidade intrínseca e espiritualidade) do que ligado a uma instituição religiosa específica (conforme confirmado pelos dados quantitativos). Houve muita presença de coping religioso espiritual, especialmente CRE positivo. Percebeu-se, na amostra estudada, várias associações do conceito de espiritualidade ao espiritismo, fato que possivelmente só é/será encontrado na cultura brasileira; pode-se criar a hipótese de que em nenhum outro lugar do mundo, a população em geral fará uma associação entre espiritualidade e espiritismo, como foi frequente na amostra estudada.

Assim sendo, pode-se concluir que fé, a religiosidade não organizacional (privada), a religiosidade intrínseca e o coping religioso espiritual são os elementos mais apontados nas conceitualizações de religiosidade e de espiritualidade na amostrada estudada.

\section{DECLARAÇÃO DE FINANCIAMENTO}

Não houve fonte de financiamento para a pesquisa.

\section{DECLARAÇÃO DA CONTRIBUIÇÃO DOS AUTORES:}

Certificamos que todos os autores participaram suficientemente do trabalho para tornar pública sua responsabilidade pelo conteúdo. A contribuição de cada autor pode ser atribuída como se segue:

C. S. S. C. e A. M. A. contribuíram para a conceitualização, investigação e visualização do artigo e fizeram a redação total do artigo.

\section{DECLARAÇÃO DE CONFLITOS DE INTERESSE}

Os autores declaram que não há conflitos de interesse no manuscrito submetido.

\section{REFERÊNCIAS}

Bardin, L. (2011). Análise de Conteúdo. São Paulo: São Paulo Edições.

Curcio, C. S. S. (2013). Validação da versão em Português da "Brief Multidimensional Measure of Religiousness/ Spirituality" ou "Medida Multidimensional Breve de Religiosidade/Espiritualidade" (BMMRS-P). Dissertação (Mestrado em Saúde) - Faculdade de Medicina, Universidade Federal de Juiz de Fora, Juiz de Fora.

Curcio, C. S. S.; Moreira-Almeida, A. \& Lucchetti, G. (2015). Validation of the Portuguese Version of the Brief Multidimensional Measure of Religiousness/Spirituality (BMMRS-P) in Clinical and Non-clinical Samples. Journal of Religion and Health, 54(2), 435-448.

Curcio, C.S.S. (2018). Investigação dos conceitos de religiosidade e espiritualidade em amostra clínica e não clínica em contexto brasileiro: um estudo quali quantitativo. Tese (Doutorado em Saúde)- Faculdade de Medicina, Universidade Federal de Juiz de Fora, Juiz de Fora. 


\section{H NTERAC̄öEM IT PSICOLOGIA}

Curcio, C.S.S. \& Moreira-Almeida, A. (2018). Who does believe in life after death. Brazilian Data from Clinical and Nonclinical Samples. Journal of Religion and Health. 58(4), 1217-1234. https://doi.org/10.1007/s10943-018-0723-y

Dalgalarrondo, P. (2006). Relações entre duas dimensões fundamentais da vida: saúde mental e religião. Revista Brasileira de Psiquiatria, 28(3), 177-178.

Demo, P. (1998). Pesquisa qualitativa. Busca de equilíbrio entre forma e conteúdo. Revista Latino Americana de Enfermagem, 6(2), 89-104.

Erlandson, S. (2000). Spiritual but Not Religious: a call to Religious Revolution in America. New York: Paperback.

Ferretti, S. (2001). Notas sobre o sincretismo religioso no Brasil - modelos, limitações e possibilidades. Tempo, 6(11), 13-26.

Godoy, A. S. (1995). Introdução à pesquisa qualitativa e suas possibilidades. RAE - Revista de Administração de Empresas, 35(2), 57-63.

Hufford, D. J. (2005). An analysis of the field of Spirituality, Religion and Health (S/RH): Templeton Advanced. ACPE Research. Disponível em: http://www.metanexus.net/ archive/templetonadvancedresearchprogram/pdf/ TARPHufford.pdf. Acesso em: 17 set. 2017

Idler, H. L. (1987). Religious involvement and the health of the elderly: some hyphotesis and an initial test. Social Forces, 66, 226.

Koenig, H. G. (2008). Concerns about measuring "spirituality" in research. Journal of Nervous and Mental Disease, 196(5), 349-355.

Koenig, H. G.; King, D. E. \& Carson, V. B. (2012). Handobook of Religion and Health. 2nd. ed. Oxford: Oxford University Press.

Koenig, H. G.; McCulloug, M. \& Larson, D. B. (2001). Handbook of religion and health: a century of research reviewed. New York: Oxford University Press.

Lucchetti, G.; Lucchetti, A. L. G.; Avezum, A. (2011). Religiosidade, Espiritualidade e Doenças Cardiovasculares. Revista Brasileira de Cardiologia, 24, 5557.
Martins, H. H. T. S. (2004). Metodologia qualitativa de pesquisa. Educação e Pesquisa, 30(2), 289-300.

Miarelli, A. V. T. C. \& Silva, J. V. (2011). Adaptação cultural da Brief Multidimensional Measure of Religiousness/ Spirituality. Dissertação (Mestrado em Bioética), Universidade do Vale do Sapucaí, Pouso Alegre.

Moreira-Almeida, A.; Lotufo Neto, F. \& Koenig, H. G. Religiousness and mental health: a review. Revista Brasileira de Psiquiatria, 28(3), 242-250.

Moreira-Almeida, A.; Pinsky, I., Zaleski, M. \& Laranjeira, R. (2010). Envolvimento religioso e fatores sociodemográficos: resultados de um levantamento nacional no Brasil. Revista de Psiquiatria Clínica, 37(1), 1215.

Pargament, K. I. (2009). The Psychology of Religion and Spirituality? Yes and No. International Journal for the Psychology of Religion, 9(1), 3-16. Disponível em: https:// www.tandfonline.com/doi/abs/10.1207/

s15327582ijpr0901_2?journalCode=hjpr20\&. Acesso em: 11 jul. 2018.

Pew Research Center (Dec.,2012). The global religious Landscape. Disponível em: http://www.pewforum.org/ 2012/12/18/global-religious-landscape-exec/ Acesso em: 08 jan. 2019.

Turner, W. C. (1993). A generation of seekers: The spiritual journeys of the baby boom generation. San Francisco: Harper.

Stark, R. (2015). The Triumph of Faith: Why the World Is More Religious than Ever. Intercollegiate Studies Institute.

Tsuang, M. T.; Simpson, J. C.; Koenen, K. C.; Kremen, W. S. \& Lyons, M. J. Spiriwell-being and health. Journal of Nervous and Mental Disease, 195(8), 673-680.

Turner, R. P.; Lukoff, D.; Barnhouse, R. T. \& Lu, F.G. Religious or spiritual problem. A culturally sensitive diagnostic category in the DSM-IV. Journal of nervous and mental disease, 183(7), 435-444. 